\title{
Self-Compassion and Forgiveness among Senior High School Students: A Correlational and Comparative Study
}

\author{
Mungin Eddy Wibowo*, (D) Rohmatus Naini \\ Universitas Negeri Semarang, Indonesia \\ @mungineddy@mail.unnes.ac.id*
}

\section{Article Information:}

Received January 22, 2021

Revised January 28, 2021

Accepted January 29, 2021

Keywords: forgiveness; Selfcompassion; students

\begin{abstract}
The problem of low self-compassion and forgiveness in schools causes students to often feel stress and depression, blame themselves, and label themselves to do self-harm. The inability to accept oneself leads to the rejection of unpleasant experiences, failure, and imperfection. This study aims to examine the relationship between self-compassion and forgiveness among students at three Senior High Schools located in the City of Semarang, Indonesia. There were 178 students who were involved in this study with the age range from 14 to 17 years old. The authors used the self-compassion scale, which has 26 items by measuring six sub-aspects including self-kindness, self-judgment, common humanity, isolation, mindfulness, and over-identification. The author used 10 items of the trait forgiveness scale (TFS). The results showed that there is a positive relationship between self-compassion and forgiveness and showed no differences between self-compassion and forgiveness when viewed by gender.
\end{abstract}

\section{INTRODUCTION}

This form of caring for others is part of the character of being humble, but there are still many who care about others but do not love themselves. Self-compassion is the provision of understanding and kindness to yourself for experiences of failure or mistakes made by not giving judgment to yourself. In addition, with self-compassion, individuals do not overly criticize themselves for their indigestion, weakness and failure (Neff, 2003). Allen \& Leary (2010) interpret self-compassion as a strategy for dealing with problems. When oneself are able to admit the feelings that you have in a problem and when the problem comes, then you give more love to yourself and accept the problem as part of life. Self-compassion will try to do the best by minimizing suffering in the future because self-compassion has 2 sides, namely happiness and suffering (Prama, 2013).

Neff (2004) defines self-compassion as good behavior towards oneself which is when experiencing self-criticism of pain, inability and failure. Neff (2003) categorizes that 3 components of self-compassion are self-goodness, general human perception and mindfulness which become a unity between self and others. However, this concept is different from selfesteem but the similarity is how individuals are able to accept themselves. Of course, selfcompassion is an important emotional regulation strategy because it is a protective factor affecting mental health and an effort to change negative emotions to be more mindful in unpleasant experiences by accepting and understanding without avoiding them. Self-

How to cite:

E-ISSN:

Published by:
Wibowo, M., \& Naini, R. (2021). Self-Compassion and Forgiveness among Senior High School Students: A Correlational and Comparative Study. Islamic Guidance and Counseling Journal, 4(1).

https://doi.org/10.25217/igcj.v4i1.1370

2614-1566

Institut Agama Islam Ma'arif NU (IAIMNU) Metro Lampung 
compassion moderated the relationship between lack of forgiveness and symptoms of depression. So that this self-compassion can help individuals to have more positive emotions.

Self-kindness refers to the tendency to care for and understand yourself rather than criticizing or judging yourself. Self-judgment tends to reject feelings, thoughts, urges, actions. Individuals who have common humanity view more that life difficulties and failure are things that are experienced by humans, but the opposite is that individuals who experience isolation see imperfection or failure as embarrassing and need to withdraw and feel alone. Individuals with mindfulness tend to accept every event, while over-identification is more concerned with being fixated on all their faults and not accepting and exaggerating their failure. The results of research conducted by Sakiz \& Saricam (2015) show that self-compassion is related to forgiveness.

Forgiveness is defined as the process of reducing disappointment and resentment related to negative emotions, motivation and cognition. So that the visible behavior is reducing individuals to take revenge. With forgiveness, it tends to reduce unwillingness to forgive which has an impact on reducing negative emotions such as hatred and revenge. In addition, individuals who do forgiveness will be better able to use the right coping strategies and can manage the stress they face. However, research results also prove that forgiveness has no connection with happiness (Safaria, 2014). This is in line with the research of Batik et al. (2017) which explains that there is a positive but low relationship between forgiveness and happiness, and forgiveness is found as a significant predictor of subjective happiness. Forgiveness is personal, independent of gender, based on the results of research conducted by Asici (2019) that there is no difference in forgiveness between women and men. However, research conducted by (Neff \& Pommier, 2013) shows that women are more forgiving than men.

Some of the factors that influence individuals to forgive include empathy, common sense, emotional maturity and how they interpret pain and negative feelings (Kamat, Jones \& Row, 2006). Individuals will be more forgiving if they have the prevalence of intimacy in a relationship, so they prefer to forgive. Furthermore, when viewed from the reasons for forgiveness, namely responsibility for mistakes, correction of errors, results or impacts of mistakes, the severity of the errors, the process of apologizing and the subject who made mistakes where everything will be taken into consideration in doing forgiveness (Bugay \& Demir, 2011) .

Problems encountered when individuals have low self-compassion and low forgiveness are more likely to ruminate on unpleasant experiences then blame themselves and often end up in self-harm or self-injury or wrong behavior. It is further explained that self-compassion can have the effect of eliminating depression as a healing skill (Weiner \& Rappaport, 2014). When individuals lack forgiveness, there will be a connection with depressive symptoms which is indicated by psychological incompatibility so that this is closely related to mental health (Chung, 2016).

It is important to research that self-compassion and forgiveness are needed by students. School counselors identify this as a basic effort to develop social aspects of personal and prevent deviant behaviors. The purpose of this study is to determine the relationship between self-compassion and forgiveness and also to examine gender. The results of this study can be used as the selection and preparation of appropriate interventions in guidance and counseling services in schools.

High school students with adolescent characteristics are closely related to intrapersonal and interpersonal conflicts due to a lack of self-evaluation. To explore the relationship between self-compassion and forgiveness, it is necessary to review research with the characteristics of adolescents in Indonesia, especially in the city of Semarang. Previous research has often looked at the periodicity of young adults, especially in the context of 
relationships with partners, helper characteristics, and or individuals with clinical problems. Meanwhile, this research focuses on self-compassion and forgiveness which is owned by adolescents with an age range of 14-17 years.

\section{Rationale of the Current Study}

Based on a review of previous research and the factual condition that student problems are often caused by a lack of acceptance of what has been done by oneself and others. Low self-compassion is known to be due to rejection of failures, imperfections and mistakes. Labelling your self makes a person blame themselves, hate themselves and do negative things such as deviant behavior. In addition, the factor of the inability to apologize to self and others causes negative emotions and results in revenge and maladaptive behavior. The relationship between these two variables needs to be tested and reviewed the differences in selfcompassion and forgiveness based on gender.

\section{Hypotheses}

1. There is a significant correlation between self-compassion and forgiveness

2. There are differences in self-compassion and forgiveness based on gender.

\section{METHODS}

\section{Research Design}

This correlational research uses a survey method which is carried out in an asynchronous system through a google form that has been provided by researchers and collaborating school counselors. The study took approximately 2 months to complete.

\section{Participants}

This study involved 178 students from 3 Senior high schools in the city of Semarang. The sample selection was done by purposive random sampling. There were 76 students $(42.7 \%)$ male and 102 students $(57.3 \%)$ female. The age range of participants is $14-17$ years.

\section{Instruments}

The measurement of self-compassion uses a self-compassion scale (Neff, 2003), totaling 26 items by measuring 6 sub-aspects including self-kindness, self-judgment, common huminity, isolation, mindfulness and over-identification. Each item uses a Likert scale with a range of 4 choices including ( $4=$ very suitable to $1=$ very inappropriate). This adaptation to an internal consistency coefficient about .79. Furthermore, a forgiveness measurement was also carried out using the trait forgiveness scale (TFS) with the number of items 10 . The Likert scale used was also 4 options, namely $(1=$ very inappropriate to $4=$ very suitable). The internal consistency coefficient on this scale is .67.

\section{Data Analysis}

The data analysis used was correlation and saw the difference between self-compassion and forgiveness based on gender with significant correlation $(p>.05)$ and $t$ test $(p<.05)$. The statistical analysis used was SPSS 25.

\section{RESULTS AND DISCUSSION}

\section{Results}

Based on the results of data analysis, the table 1 showed the demographical information of participants and table 2 showed correlational test analysis and independent $\mathrm{t}$ test results. 
Table 1. The demographical information of participants

\begin{tabular}{lll}
\hline Categories & $\mathrm{N}$ & Percentage \\
\hline Gender & 76 & $42.7 \%$ \\
$\quad$ Male & 102 & $57.3 \%$ \\
Female & & \\
Age (years olds) & 3 & $1.7 \%$ \\
14 & 23 & $12.9 \%$ \\
15 & 140 & $78.7 \%$ \\
16 & 12 & $6.7 \%$ \\
17 & & \\
Class & 59 & $33.1 \%$ \\
10 & 58 & $32.5 \%$ \\
11 & 61 & $34.4 \%$ \\
12 & & \\
\hline
\end{tabular}

Tabel 2. Correlational test analysis and independent t-test

\begin{tabular}{llllll}
\hline Variabel & $\mathrm{M}$ & SD & $P$ & $\mathrm{r}$ & T test $(p)$ \\
\hline Self-compassion & 75.612 & 5.726 & .002 & .227 & .723 \\
Forgiveness & 26.044 & 3.500 & & & .462 \\
\hline
\end{tabular}

Table 2 showed that self-compassion has $\mathrm{M}=75,612$ and $\mathrm{SD}=5,726$, while for forgiveness, it is $\mathrm{M}=26,044$ and $\mathrm{SD}=3.5$. The Pearson correlation test shows that $\mathrm{p}=.002<$ .05 means that there is a correlation between self-compassion and forgiveness. When viewed from gender, the $\mathrm{p}$ value for self-compassion is .723 and forgiveness is .462 , because $p>.05$ there is no difference in self-compassion and forgiveness when viewed from gender.

\section{Discussion}

High self-compassion will tend to be able to deal with the suffering of others without feeling overwhelmed by personal pressure. This is also related to how individuals forgive others (Neff \& Pommier, 2013). Self-compassion is indicated gently to oneself in response to negative events. The opportunity to recognize that problems are a normal part of life. This means that when an individual has self-compassion, when he experiences a big problem, he will think that the problems experienced can also be experienced by other people with heavy categories, so that a new belief emerges that negative events are not worse than experiences experienced by others (Leary et al., 2007).

Roxas, David \& Calinger (2014) explained that self-compassion also involves the suffering of others, but the process also opens awareness to empathize, accept mistakes instead of avoiding. The characteristics of individuals who do forgiveness, namely choosing to make peace, improve the situation, make compassionate comments, take special actions and become a continuous, lifelong process. Sakiz \& Bicer (2015) explains that selfcompassion is related to forgiveness with others. Forgiveness is positively correlated with interpersonal adjustment and psychological well-being (Yip \& Tse, 2009; Allemand, Steiner \& Hill., 2013; Bowker et al., 2011)

Sakiz \& Saricam (2015), forgiveness is a process of transition from feelings of revenge to tolerance and empathy as an effort to repair damaged correlation. There is no need to deny past mistakes and cover up mistakes. Individuals who are willing to forgive others will have higher life satisfaction, better welfare, increased self-esteem, and decreased anxiety.

The benefits of self-compassion can be described as a form of individual motivation to constructively improve and organize themselves in interpersonal correlation so that individuals are able to learn from the experiences they go through (Breines \& Chen, 2012). Agreeing with this, Krause \& Ellison (2003) interpret forgiveness as an individual mechanism regulating interpersonal correlation and psychological well-being. So that this process can replace the self-harm behavior that comes from self-denial. 
Individuals who label themselves as a form of rejection and disappointment over the imperfections that have been done so that manifestations of hurting themselves. There is need for harmony in self-compassionate and forgiveness in order to act consistently. Individuals who have self-compassionate will be able to manage stress and have more positive feelings about themselves and will be appreciated by others (Leary et al., 2007). So individuals who are compassionate with themselves tend to have high self-esteem and are distant from narcissism, self-enhancing, arrogance. Enright in Batik et al., (2017) explains that in forgiveness there is a willingness to leave hatred, negative judgments and indifference. Primarily, improving the quality of compassion, generosity and self-love.

In school settings, forgiveness is very important because it can be used as an effective coping response in correcting aggressive affective situations in the context of bullying at school. In the process of forgiveness, empathy is important (Davis \& Gold, 2010). It is reinforced by Wilkowski, Robinson \& Troop-Gordon (2010) that when conflict arises, cognitive control functions to generate forgiveness and reduce high anger. Bullying problems that are also often found in schools have a close correlation with forgiveness. When experiencing oppression, a high level of forgiveness will reduce emotional wounds in response to past experiences (Egan \& Todorov, 2009), forgiveness is correlated with positive coping strategies (Flanagan et al., 2012). Implications in guidance and counseling services, as a preventive and curative effort, interventions can be carried out such as group or individual counseling that involves elements of forgiveness and self-compassion.

\section{Limitations and Suggestions}

The limitation of this study is that the number of research subjects is not large enough so that further research can be developed with a large number of samples. In addition, there is a need for correlative research that requires moderating or mediating variables. As a curative effort, it is necessary to experiment with group and individual counseling service strategies with several approaches, such as compassion-focused therapy or mindfulness-based cognitive therapy.

\section{Implications}

This study has implications for counseling services in schools as part of character education. Counselors play an important role in fostering and developing self-compassion and forgiveness in adolescents. These two variables are part of the individual's character strengths. If the good character is given by students through understanding and then it can be expected to behave with these good characters (Purwanto, Wibowo, \& Mulawarman, 2018).

\section{CONCLUSSION}

Problems of self-compassion and forgiveness are often encountered due to a lack of acceptance, unpreparedness for failure and self-imperfection that make individuals have low self-esteem as well. It is not uncommon for maladaptive problems such as stress or depression, bullying and self-harm to be encountered in students. This study has tested the correlation between self-compassion and forgiveness, the result is that the two variables have a positive correlation. In addition, if it is viewed from gender, it is found that there is no difference in the self-compassion of male and female students. It is the same with the results of the forgiveness analysis that there is also no difference in scores between male and female students. It needs to be studied further with a larger sample size and also with other control variables that also support the findings of this research. Experimental research and development for self-compassion and forgiveness are also needed so that they can be implemented in schools as part of character education. 


\section{ACKNOWLEDGMENTS}

Thanks for the school counselors and students who were participated in this study.

\section{AUTHOR CONTRIBUTIONS STATEMENT}

Authors conduct the pre-data collection process and write the manuscript together. MEW preparing the instrument and $\mathrm{RN}$ as the enumerator.

\section{REFERENCES}

Allemand, M., Steiner, M., \& Hill, P. L. (2013). Effects of a forgiveness intervention for older $\begin{array}{llll}\text { adults. Journal of } & \text { counseling }\end{array}$ https://psycnet.apa.org/doi/10.1037/a0031839

Allen, A. B., \& Leary, M. R. (2010). Self-Compassion, stress, and coping. Social and personality psychology compass, 4(2), 107-118. https://doi.org/10.1111/j.17519004.2009.00246.x

Allen, A. B., Goldwasser, E. R., \& Leary, M. R. (2012). Self-compassion and well-being among older adults. Self and Identity, 11(4), 428-453. https://doi.org/10.1080/15298868.2011.595082

Asici, E. (2019). The Role of Forgiveness Flexibility in Predicting of Adolescents' WellBeing. Erzincan Üniversitesi Ë̆itim Fakültesi Dergisi,21(3), 17-31. https://doi.org/10.17556/erziefd.440497

Batik, M. V., Bingöl, T. Y., Kodaz, A. F., \& Hosoglu, R. (2017). Forgiveness and Subjective Happiness of University Students. International Journal of Higher Education, 6(6), 149-162. Google Scholar

Bowker, J. C., Thomas, K. K., Norman, K. E., \& Spencer, S. V. (2011). Mutual best friendship involvement, best friends' rejection sensitivity, and psychological maladaptation. Journal of Youth and Adolescence, 40, 545-555. https://doi.org/10.1007/s10964-010-9582-x

Breines, J. G., \& Chen, S. (2012). Self-compassion increases self-improvement motivation. Personality and Social Psychology Bulletin, 38(9), 1133-1143. https://doi.org/10.1177\%2F0146167212445599

Bugay, A., \& Demir, A. (2011). Psychometric properties of the Turkish version of trait shame and guilt scale. Eurasian Journal of Educational Research, 45, 17-30. Google Scholar

Chung, M. S. (2016). Relation between lack of forgiveness and depression: The moderating effect of self-compassion. Psychological reports, 119(3), 573-585. https://doi.org/10.1177\%2F0033294116663520

Davis, J. R., \& Gold, G. J. (2011). An examination of emotional empathy, attributions of stability, and the link between perceived remorse and forgiveness. Personality and Individual Differences, 50(3), 392-397. https://doi.org/10.1016/j.paid.2010.10.031

Egan, L. A., \& Todorov, N. (2009). Forgiveness as a coping strategy to allow school students to deal with the effects of being bullied: Theoretical and empirical discussion. Journal of Social and Clinical Psychology, 28(2), 198-222. https://doi.org/10.1521/jscp.2009.28.2.198

Flanagan, K. S., Hoek, K. K. V., Ranter, J. M., \& Reich, H. A. (2012). The potential of forgiveness as a response for coping with negative peer experiences. Journal of Adolescence, 35(5), 1215-1223. https://doi.org/10.1016/j.adolescence.2012.04.004

Kamat, V. I., Jones, W. H., \& Row, K. L. (2006). Assessing forgiveness as a dimension of personality. Individual Differences Research, 4(5). Google Scholar

Krause, N., \& Ellison, J. G. (2003). Forgiveness by God, forgiveness of others, and psychological well-being in late life. Journal for the Scientific Study of Religion, 42(1), 77-93. https://doi.org/10.1111/1468-5906.00162 
Leary, M. R., Tate, E. B., Adams, C. E., Batts Allen, A., \& Hancock, J. (2007). Selfcompassion and reactions to unpleasant self-relevant events: the implications of treating oneself kindly. Journal of personality and social psychology, 92(5), 887. Google Scholar

Neff, K. D. (2003). The development and validation of a scale to measure selfcompassion. Self and identity, 2(3), 223-250. https://doi.org/10.1080/15298860309027

Neff, K. (2004). Self-compassion and psychological well-being. Constructivism in the human sciences, 9(2), 27. Google Scholar

Neff, K. D., \& Pommier, E. (2013). The Relationship between Self-compassion and Otherfocused Concern among College Undergraduates, Community Adults, and Practicing Meditators. Self and Identity, 12(2), 160-176. https://doi.org/10.1080/15298868.2011.649546

Prama, G. (2013). Sadness, Happiness, Blissfulness. Gramedia Pustaka Utama.

Roxas, M. M., David, A. P., \& Caligner, E. T. (2014). Examining the relation of compassion and forgiveness among Filipino counselors. Asian Journal of Social Sciences \& Humanities, 3(1), 53-62. Google Scholar

Safaria, T. (2014). Forgiveness, gratitude, and happiness among college students. International Journal of Public Health Science (IJPHS), 3(4), 241-245.

Sakiz, H., \& Sariçam, H. (2015). Self-compassion and forgiveness: The protective approach against rejection sensitivity. The International Journal of Human and Behavioral Science, 1(2), 10-21. https://doi.org/10.19148/ijhbs.58217

Weiner, E. T., \& Rappaport, L. (2014). Mindfulness and focusing-oriented arts therapy with children and adolescents. Mindfulness and the arts therapies: Theory and practice, 248261. Google Scholar

Wilkowski, B. M., Robinson, M. D., \& Troop-Gordon, W. (2010). How does cognitive control reduce anger and aggression? The role of conflict monitoring and forgiveness processes. Journal of personality and social psychology,98(5), 830. https://psycnet.apa.org/doi/10.1037/a0018962

Yip, T. H., \& Tse, W. S. (2009). Relationship among dispositional forgiveness of others, interpersonal adjustment and psychological well-being. Personality and Individual Differences, 46(3), 365-368. https://doi.org/10.1016/j.paid.2008.11.001

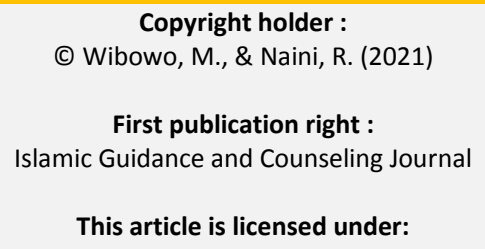

